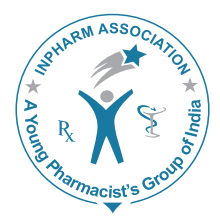

\title{
Formulation and development of multiparticulates dosage form of propranolol hydrochloride
}

\author{
Niti Yadav ${ }^{1 *}$, Alka Lohani ${ }^{1}$

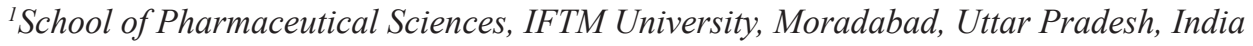

\begin{abstract}
Aim: The objective of the present research work was to develop stable extended release (ER) pellets of propranolol hydrochloride, an antihypertensive drug, for which drug release profile is compared with reference to the multiple conventional dosage form i.e. marketed product "Inderal LA" (160 mg). Method: ER formulations were developed using fluid bed layering and coating techniques on sugar spheres. Pellets were characterized in reference to the drug content, size distribution, scanning electron microscopy (SEM); dissolution study of various formulations was performed in $1.2 \mathrm{pH} \mathrm{HCl}$ buffer for 1.5 hours followed by testing in $6.8 \mathrm{pH}$ phosphate buffer for 24 hours (USP Criteria). Stability studies of the optimized formulation were carried out for a period of 30 days at $40 \pm 2^{\circ} \mathrm{C}$ and $75 \pm 5 \%$ relative humidity and were found to be stable. SEM photograph confirmed that the prepared pellets were spherical in nature. The drug content of the formulations was found in the range of 98 to $99.7 \%$ and the mean particle size of the drug loaded pellets was in the range of 1190 to $420 \mu \mathrm{m}$ (F1 to F3 formulation). Result and Conclusion: Results revealed that EC N50: TEC $(90: 10)$ is the best combination of polymer which controls the drug release profile up to 24 hours. Moreover similarity of release between optimized formulation and Inderal LA was confirmed by calculation of two factors $\mathrm{f} 1$ (difference factor) $=1.95$ and $\mathrm{f} 2$ (similarity factor) $=99$ from the dissolution data. The kinetic data of ER pellets formulation showed good fit in Korsmeyer-Peppas model and followed by Higuchi kinetic drug release.
\end{abstract}

Key words: Fluidized bed processor, Fickian, Inderal LA, Non-Fickian, Sugar spheres

\section{INTRODUCTION}

During the past few decades, various types of oral extended release formulations have been developed to improve the clinical efficacy of the drug having a short half-life, as well as patient compliance. A critical role for an extended

\begin{tabular}{|c|c|}
\hline \multicolumn{2}{|c|}{ Access this article online } \\
\hline Journal Sponsor & \multirow[b]{2}{*}{$\begin{array}{l}\text { Website: } \\
\text { www.jyoungpharm.org }\end{array}$} \\
\hline \multirow{2}{*}{ www.phcog net } & \\
\hline & $\begin{array}{l}\text { DOI: } \\
\text { 10.5530/jyp.2014.1.3 }\end{array}$ \\
\hline
\end{tabular}

release formulation is in the therapy of cardiovascular disease, whereby the blood level of a medicament must be maintained at the steady state level to achieve the desired therapeutic effect.

As it is well-known, propranolol hydrochloride formulations are effective only for a few hours, because of biological modification and/or elimination of the medication in the body. ${ }^{1}$ Since the half-life of propranolol hydrochloride is only 3-4 h; therefore, repeated doses must be taken at frequent intervals to obtain a long-term therapeutic level of drug. Furthermore, propranolol hydrochloride usually dissolves readily in the digestive juices and the total dosage is immediately fed into the

*Address for correspondence:

Ms. Niti Yadav, School of Pharmaceutical Sciences, IFTM University, Lodhipur Rajpoot, Delhi Road, (NH-24), Moradabad-244 102,

Uttar Pradesh, India. E-mail: nitiyadav.pharma@gmail.com 
blood stream. After high initial peak concentrations, the level of drug in the bloodstream constantly decreases because of the biological elimination, so there is little or no therapeutic effect at the end of the period between doses. As a result, the therapeutic effect fluctuates between doses corresponding to the peaks and valleys in the level of drug in the blood.

The most conventional way to make extended release formulation is a tablet. The tablet can be either monolithic matrix tablet or heterogeneous matrix tablet or tablet coated with release controlling membrane. Tablet based matrix formulations have variations in gastric emptying rates and overall transit times leading to intra- and intersubject variability of plasma profiles. The other way to make extended release formulation is multiparticulates formulation based on pellets or spheroids. Pelletized products not only offer flexibility in dosage form design and development, but are also utilized to improve the safety and efficacy of active ingredients or substances. Pellets offer significant therapeutic advantages over single unit dosage forms like matrix-based tablets because pellets disperse freely in the gastrointestinal tract; they invariably maximize drug absorption, reduce peak plasma fluctuations, and minimize potential side-effects. The pellets also reduce variations in gastric emptying rates and overall transit times. Thus, intra-and inter-subject variability of plasma profiles, which are common with single unit regimens, is minimized.

Hence, there is a need to develop a drug delivery system for propranolol hydrochloride in the form of extended release (ER) multiparticulates, ${ }^{2,3}$ which can deliver, preferably for $24 \mathrm{~h}$.

In this study, ER pellets of propranolol hydrochloride were formulated and evaluated the ratio of polymers for coating, particle size of pellets and drug release profile. Hydroxy propyl methyl cellulose (HPMC) E5 and ethyl cellulose (EC) N50 were the polymers used for the coating of drug loaded pellets. Triethyl citrate (TEC) was used as a pore forming agent to modify the release of the drug. Research showed that for drug-layered sugar spheres coated with an aqueous pseudolatex dispersion of EC, drug release was mainly driven by osmosis through aqueous pores and cracks. ${ }^{4}$ Both highly soluble drug and sugar from the core can contribute significantly to the osmotic pressure gradient ${ }^{5,6}$ across the rate controlling membrane. This drives the diffusion of water and a buildup of hydrostatic pressure in the core. Consequently, the ER membranes are subjected to tensile stress, which can lead to structural changes and eventual stress cracks and rupture of the film. ${ }^{7}$ Formulation development process $^{8,9}$ had undergone the preformulation studies, formulating the product, optimizing the formula and comparing the in vitro dissolution profile of the final formulation with the innovator (Inderal LA).

\section{MATERIALS AND METHODS}

\section{Materials}

Propranolol hydrochloride was obtained from IPCA Laboratories Mumbai, HPME E5 from Colorcon, EC N50 from Aqualon and all other chemicals and ingredients used were of analytical grade.

\section{Methods}

\section{Preparation of standard plot at different $\mathrm{pH}$}

Standard plot of the drug was prepared by ultraviolet (UV) spectrophotometer in the following dissolution media distilled water, $0.1 \mathrm{~N} \mathrm{HCl}$ (pH: 1.2) and phosphate buffer pH 6.8.

A stock solution of propranolol hydrochloride having a concentration of $1000 \mu \mathrm{g} / \mathrm{ml}$ was prepared in abovementioned dissolution media, respectively. Then by appropriate dilution with respective media 20, 40, 60, 80, and $100 \mu \mathrm{g} / \mathrm{ml}$ concentration solution was made from working stock solution and absorbance of their solution was taken at $320 \mathrm{~nm}$, using carry 50 double beam spectrophotometer. A graph between concentration (x-axis) and absorbance (y-axis) was plotted and was found to obey Beer Lambert law.

\section{Solubility}

Saturated solubility of the drug was determined by keeping the excess amount of it with dissolution media at $25^{\circ} \mathrm{C}$ in a mechanical shaker for $24 \mathrm{~h}$, to attain equilibrium. The suspension was filtered and quantified by UV spectrophotometer.

\section{Particle size}

The particle size of the drug was determined by a dry dispersion method using Malvern Mastersizer 2000.

\section{Formulation of propranolol hydrochloride pellets}

The pellets of propranolol hydrochloride were prepared by using sugar spheres. First, seal coating was done prior to drug loading on sugar spheres because they were very small in size and brittle in nature, so in order to reduce fine generation they were made hard by seal coating and also to prevent agglomeration. ${ }^{10,11}$

Journal of Young Pharmacists Vol 6 • Issue 1 • Jan-Mar 2014 
Step 1 - Seal coating: 3\% seal coating of the sugar spheres were done by preparing 5\% w/v solution of HPMC E5 in isopropyl alcohol (IPA): Dichloromethane (DCM) (50:50) and this solution was loaded on to the core sugar pellets. Then, pellets were dried for $15 \mathrm{~min}$ at $35-40^{\circ} \mathrm{C}$. The seal coated pellets were sieved using a nest of standard sieves $(1190,1000,850,710,590,500$, and $420 \mu \mathrm{m})$ shaken for $10 \mathrm{~min}$ on a sieve shaker. The pellets retained on each sieve were weighed in order to compare the size range with the innovator, after which loading of the drug was done on those pellets. ${ }^{12}$

Step 2 - Drug loading: All the ingredients were weighed out as per given formula (Table 1). The required quantity of water was taken and kept it under stirring, polyvinyl pyrrolidone K-90 and propranolol hydrochloride was added to the vortex of the solution under stirring and stirred for $20 \mathrm{~min}$. Then talc was added and stirred for $10 \mathrm{~min}$ and the dispersion was passed using nylon cloth (mesh number 20). Finally, drug was loaded using dispersion on the sugar spheres in the chamber of fluidized bed processor.

Step 3 - ER coating: Required quantity of IPA was taken and HPMC E5/TEC was added to it. Then same amount of DCM so that (IPA:DCM = 50:50) and EC N50 was added under stirring. The solution was ready for ER coating on to the drug loaded sugar spheres. In this study, experimental parameter were fixed ${ }^{9,13-16}$ (Table 1).

\section{Drug content determination or assay}

\section{Test preparation}

$277.5 \mathrm{mg}$ of coated pellets (equivalent to $160 \mathrm{mg}$ of propranolol hydrochloride) was swirled in a sonicator with methanol and was centrifuged. $2.5 \mathrm{ml}$ of clear solution was taken and diluted with methanol up to $100 \mathrm{ml}$. Absorbance was measured by UV spectrophotometer at $320 \mathrm{~nm} .{ }^{17}$

\section{Standard preparation}

$50 \mathrm{mg}$ of propranolol hydrochloride was taken and diluted up to $100 \mathrm{ml}$ with methanol. $4 \mathrm{ml}$ of the solution was taken and diluted up to $50 \mathrm{ml}$ with methanol. Absorbance was measured by UV spectrophotometer at $320 \mathrm{~nm}$.

Drug content was calculated by following formula:

Quantity of propranolol hydrochloride $(\mathrm{mg})$ in finished dosage form (capsule)

\section{$(\mathrm{LC} / \mathrm{D}) * \mathrm{Av} / \mathrm{As}$}

$\mathrm{L}=$ Labeled quantity of propranolol hydrochloride $(\mathrm{mg})$ in finished dosage form (capsule)

Journal of Young Pharmacists Vol 6 • Issue 1 • Jan-Mar 2014
Table 1: Composition of formulation

\begin{tabular}{|c|c|c|c|c|c|c|c|}
\hline \multicolumn{8}{|c|}{ Seal coating of core sugar coated pellets } \\
\hline \multirow{2}{*}{\multicolumn{3}{|c|}{ Ingredients }} & \multicolumn{5}{|c|}{ Quantity (g/batch) } \\
\hline & & & \multicolumn{2}{|l|}{ F1 } & \multicolumn{2}{|l|}{ F2 } & F3 \\
\hline \multicolumn{3}{|c|}{ Sugar spheres (\#25/30) } & 780 & & \multicolumn{2}{|l|}{ - } & - \\
\hline \multicolumn{3}{|c|}{ Sugar spheres (\#30/35) } & - & & \multicolumn{2}{|l|}{780} & - \\
\hline \multicolumn{3}{|c|}{ Sugar spheres (\#40/50) } & - & & \multicolumn{2}{|l|}{-} & 400 \\
\hline \multicolumn{3}{|l|}{ HPMC (E5) } & 23.4 & & \multicolumn{2}{|l|}{23.4} & 20 \\
\hline \multicolumn{3}{|l|}{ IPA } & 223.3 & & \multicolumn{2}{|l|}{223.3} & 190 \\
\hline \multicolumn{3}{|l|}{$\mathrm{DCM}$} & 223.3 & & \multicolumn{2}{|l|}{223.3} & 190 \\
\hline \multicolumn{8}{|c|}{ Drug loading on seal coated sugar spheres } \\
\hline \multirow{2}{*}{\multicolumn{3}{|c|}{ Ingredients }} & \multicolumn{5}{|c|}{ Quantity (g/batch) } \\
\hline & & & F1 & & F2 & & F3 \\
\hline \multicolumn{3}{|l|}{ Propranolol } & 561.4 & & 561.4 & & 490.04 \\
\hline \multicolumn{3}{|l|}{ PVP K90 } & 28 & & 28 & & 24.50 \\
\hline \multicolumn{3}{|l|}{ Talc } & 28 & & 28 & & 24.50 \\
\hline \multicolumn{3}{|c|}{ Seal coated pellets } & 281.15 & & 281.19 & & 250 \\
\hline \multicolumn{3}{|l|}{ Water } & 4200 & & 4200 & & 3378 \\
\hline \multicolumn{8}{|c|}{ Coating of drug loaded pellets* } \\
\hline \multirow[t]{2}{*}{ Ingredients } & \multicolumn{7}{|c|}{ Quantity (g/batch) } \\
\hline & F1 (A) & F1 (B) & F1 (C) & F2 (A) & F3 (A) & F3 (B) & F3 (C) \\
\hline EC (N50) & 23.1 & 23.1 & 25 & 18.75 & 22.5 & 22.5 & 22.5 \\
\hline HPMC (E5) & 9.1 & 9.1 & 6.25 & - & 6.25 & - & - \\
\hline TEC & - & - & - & - & - & 2.25 & 2.25 \\
\hline IPA & 313.5 & 313.5 & 297.0 & 178.13 & 237.0 & 237.0 & 237.0 \\
\hline $\mathrm{DCM}$ & 313.5 & 313.5 & 297.0 & 178.13 & 237.0 & 237.0 & 237.0 \\
\hline $\begin{array}{l}\text { Drug loaded } \\
\text { pellets }\end{array}$ & 300 & 300 & 250 & 250 & 250 & 250 & 250 \\
\hline & & Proce & ess para & ameter & & & \\
\hline Parameters & & & $\begin{array}{l}\text { Seal } \\
\text { coatir }\end{array}$ & & $\begin{array}{l}\text { Drug } \\
\text { loading }\end{array}$ & & $\begin{array}{c}\text { ER } \\
\text { coating }\end{array}$ \\
\hline Inlet tempera & ure $\left({ }^{\circ} \mathrm{C}\right)$ & & $35-3$ & & $59-82$ & & $35-42$ \\
\hline Product temp & erature ( & $\left.{ }^{\circ} \mathrm{C}\right)$ & $29-3$ & & $46-49$ & & 29-32 \\
\hline Exhaust temp & erature & $\left({ }^{\circ} \mathrm{C}\right)$ & $24-2$ & & $36-49$ & & $25-29$ \\
\hline Blower drive & peed $(\%$ & & $30-3$ & & $45-56$ & & $40-45$ \\
\hline Atomization a & $\mathrm{r}(\mathrm{kg} / \mathrm{cm}$ & & 1.2 & & $1.2-1.5$ & & 1.2 \\
\hline Spray rate (gr & n/min) & & $4-10$ & & $3-31$ & & $3-10$ \\
\hline Air flow (cubic & feet $/ \mathrm{mir}$ & & $16-2$ & & $29-31$ & & $55-60$ \\
\hline
\end{tabular}

${ }^{*}$ Coating percentage: F1 (A):11\% build up of EC N50: HPMC E5 (70:30). F1 (B): $14 \%$ build up of EC N50: HPMC E5 (70:30), F1 (C): $7.5 \%$ build up of EC N 50: HPMC (80:20), F2: $5 \%$ builds up of EC N50, F3 (A): $7 \%$ build up of EC N50: HPMC E5 (90:10), F3 (B): $8 \%$ build up of EC N50: TEC (90:10), F3 (C): $6 \%$ build up of EC N50: TEC (90:10). HPMC: Hydroxy propyl methyl cellulose, IPA: Isopropyl alcohol, DCM: Dichloromethane, PVP: Polyvinyl pyrrolidone, EC: Ethyl cellulose, TEC: Triethyl citrate

$\mathrm{C}$ and $\mathrm{D}$ were concentration in $\mu \mathrm{g} / \mathrm{ml}$ of USP propranolol hydrochloride RS in standard solution and capsule respectively.

$A_{v}$ and $A_{s}$ are the absorbance of the solution from the capsule and the standard solution.

Coated pellet equivalent to $160 \mathrm{mg}$ of propranolol hydrochloride were then filled in the hard gelatin capsule.

\section{Micromeritic properties of pellets}

Angle of repose $(\theta)$ was assessed to know the flowability of matrix pellets, by a fixed funnel method. Tap density and bulk 
density of the pellets was determined using tap density tester (TDT, Electrolab, India). The granule density of the pellets was determined by the displacement method using petroleum ether. For the friability test, pellets of known mass were placed in a Roche Friability tester (Electro lab Friability tester, EF -2, India) and subjected to testing at 25 RPM for 4 min (Table 2).

\section{Size distribution}

The ER coated pellets were sieved using a nest of standard sieves $(1190,1000,850,710,590,500$, and $420 \mu \mathrm{m})$ shaken for $10 \mathrm{~min}$ on a sieve shaker. The pellets retained on each sieve were weighed ${ }^{18}$ (Table 3).

\section{Surface morphology}

Morphological characteristics of ER pellets were analyzed by scanning electron microscopy (SEM).

\section{In vitro drug release}

Dissolution was carried out in USP Apparatus Type I at $320 \mathrm{~nm} .{ }^{19-21}$ In vitro drug release were performed for all the formulations using $0.1 \mathrm{~N} \mathrm{HCl}(\mathrm{pH} 1.2)$ for $1.5 \mathrm{~h}$ followed by $6.8 \mathrm{pH}$ phosphate buffer as a dissolution medium for $24 \mathrm{~h}$ at $37 \pm 2{ }^{\circ} \mathrm{C}$. The graphs were plotted by taking cumulative percentage drug release versus time.

\section{Drug release kinetic models}

Drug release mechanisms and kinetics are the two important characteristics of a drug delivery system in describing the drug release profile. To describe the kinetics of the drug release from capsule, mathematical models such as Higuchi, Korsmeyer-Peppas, Zero order, and First order were used.

\section{Stability studies}

The stability studies of the optimized formulation were carried out according to International Conference on Harmonization $(\mathrm{ICH})$ guidelines at $\left(40 \pm 2^{\circ} \mathrm{C} / 75 \% \mathrm{RH}\right)$ for 1 month and uses similarity factor $\left(f_{2}\right)$ calculation to confirm this. ${ }^{22}$

$\mathrm{f}_{2}=50 \times \log \left\{\left[1+(1 / \mathrm{n}) \sum_{\mathrm{t}=1}^{\mathrm{n}}\left(\mathrm{R}_{\mathrm{t}}-\mathrm{T}_{\mathrm{t}}\right)^{2}\right]^{-0.5} \times 100\right\}$

\section{RESULT AND DISCUSSION}

\section{Characteristics of pure drug}

The result of the standard plot in different dissolution media was found to obey Beer Lambert law given in Figure 1.

Studies were conducted and found that propranolol hydrochloride is a highly water soluble drug $(146 \mathrm{mg} / \mathrm{ml})$, if not formulated properly may readily release the drug at a faster rate and produces a toxic concentration on oral administration. Particle size of drug determined by the Malvern Mastersizer-2000 found in the range of 70-500 $\mu \mathrm{m}$ (Figure 2).

Table 2: Assay, angle of repose, tapped density, bulk density, granular density, Hausner's ratio, Carr's index, friability

\begin{tabular}{|c|c|c|c|c|c|c|c|c|}
\hline $\begin{array}{l}\text { Formulation } \\
\text { No. } \\
\end{array}$ & $\begin{array}{c}\text { Assay } \\
(\%)\end{array}$ & $\begin{array}{c}\text { Angle of repose, } \\
\theta\left({ }^{\circ}\right)\end{array}$ & $\begin{array}{c}\text { Tapped density } \\
(\mathrm{gm} / \mathrm{ml})\end{array}$ & $\begin{array}{c}\text { Bulk density } \\
(\mathrm{gm} / \mathrm{ml})\end{array}$ & $\begin{array}{c}\text { Granular density } \\
(\mathrm{gm} / \mathrm{ml})\end{array}$ & Hausner's ratio & Carr's index & $\begin{array}{c}\text { Friability } \\
(\%) \\
\end{array}$ \\
\hline Inderal & 99.7 & 26.25 & 0.53 & 0.49 & 1.02 & 1.08 & 7.50 & 0.39 \\
\hline $\mathrm{F} 1(\mathrm{~A})$ & 98.8 & 27.15 & 0.40 & 0.36 & 1.01 & 1.05 & 10.00 & 0.44 \\
\hline $\mathrm{F} 1(\mathrm{~B})$ & 99.0 & 27.29 & 0.49 & 0.42 & 1.02 & 1.16 & 14.28 & 0.33 \\
\hline $\mathrm{F} 1(\mathrm{C})$ & 99.5 & 27.35 & 0.42 & 0.36 & 1.04 & 1.16 & 14.28 & 0.51 \\
\hline $\mathrm{F} 2(\mathrm{~A})$ & 97.8 & 32.44 & 0.49 & 0.33 & 1.92 & 1.48 & 32.00 & 0.99 \\
\hline F3 (A) & 98.0 & 25.96 & 0.43 & 0.40 & 1.09 & 1.07 & 6.97 & 0.52 \\
\hline F3 (B) & 98.0 & 26.11 & 0.52 & 0.44 & 1.07 & 1.18 & 15.00 & 0.49 \\
\hline F3 (C) & 99.1 & 26.12 & 0.50 & 0.46 & 1.09 & 1.08 & 8.00 & 0.48 \\
\hline
\end{tabular}

Table 3: Characterization of innovator product and formulations

\begin{tabular}{|c|c|c|c|c|c|c|c|c|}
\hline \multirow[t]{2}{*}{ Sieve number } & \multicolumn{8}{|c|}{ Weight retained on sieve (\%) } \\
\hline & Inderal LA 160 mg & F1 (A) & F1 (B) & F1 (C) & F2 (A) & F3 (A) & F3 (B) & F3 (C) \\
\hline $16(1190 \mu \mathrm{m})$ & 1 & 0 & 2 & 1 & 0 & 0 & 0 & 0 \\
\hline $18(1000 \mu \mathrm{m})$ & 76 & 79 & 77 & 80 & 0 & 0 & 0 & 0 \\
\hline $20(840 \mu \mathrm{m})$ & 22 & 21 & 21 & 19 & 22 & 0 & 0 & 0 \\
\hline $25(710 \mu \mathrm{m})$ & 1 & - & - & - & 18 & 1 & 1 & 1 \\
\hline $30(590 \mu \mathrm{m})$ & - & - & - & - & 50 & 52 & 53 & 55 \\
\hline $40(420 \mu \mathrm{m})$ & - & - & - & - & 10 & 46 & 45 & 45 \\
\hline Collector & 0 & 0 & 0 & 0 & - & 1 & 1 & 0 \\
\hline
\end{tabular}




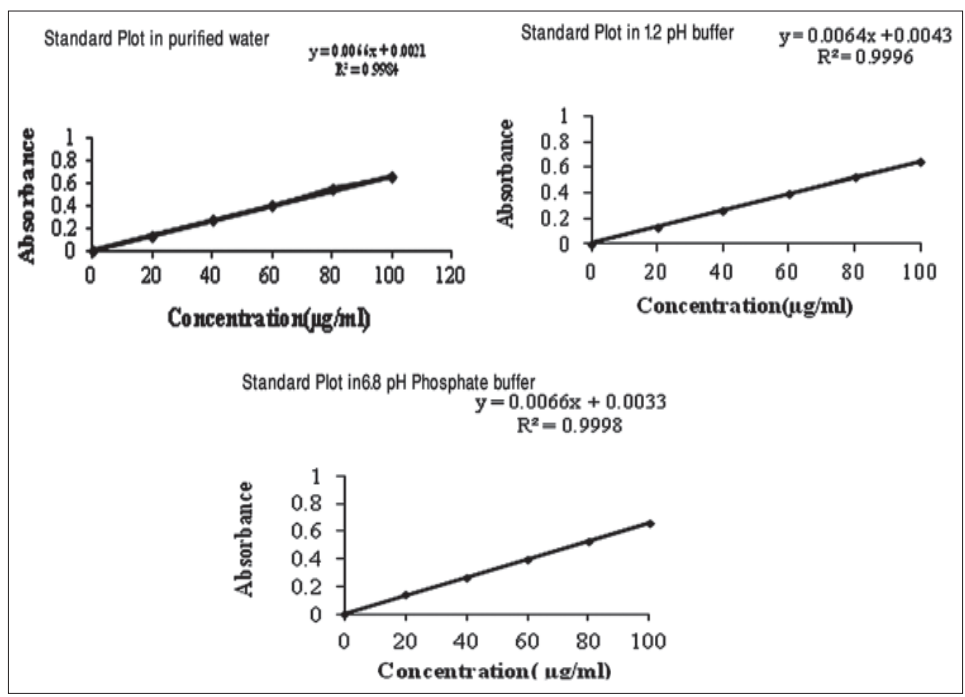

Figure 1: Standard plot of propranolol hydrochloride

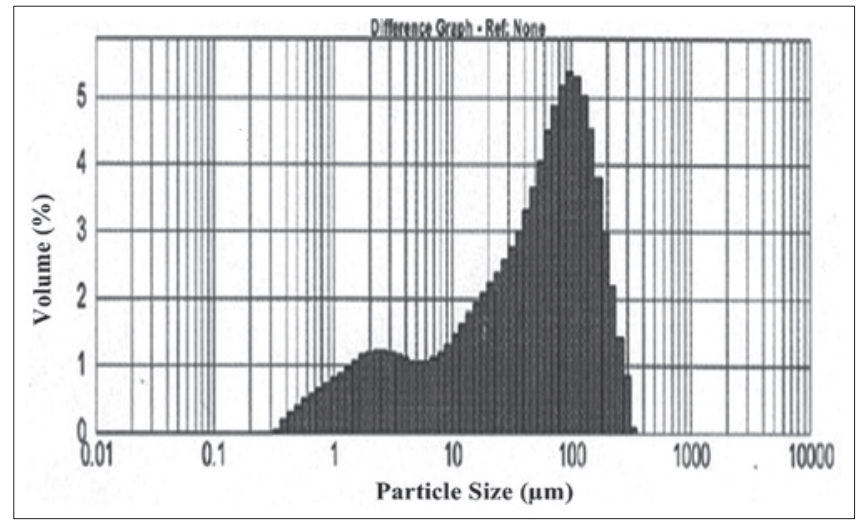

Figure 2: Particle size distribution of propranolol hydrochloride by Malvern Mastersizer 2000

\section{Evaluation of prepared formulations}

\section{Assay}

Assay of the drug in pellets indicated that the amount of drug present in the formulation 1-3 was found to be well within the USP specification limits (90-110\%) (Table 2). Based on these results, dissolution studies were conducted for formulation 1-3.

In this study, the value of angle of repose, tapped density, granular density, $\%$ Carr's Index, and Hausner's ratio values indicate good flow potential of the pellets. The friability of the propranolol pellet formulation was found to be in the range from 0.33 to 0.99 . SEM image Figure 3 shows that the pellets had a satisfactory surface morphology and also the pellets are spherical in nature not dumbbell shaped. ${ }^{23}$

\section{Pellet size}

The result obtained from particle size analysis showed seal coated and drug loaded pellets of F1 formulation have size range of $1190-840 \mu \mathrm{m}, \mathrm{F} 2$ formulation have $840-420 \mu \mathrm{m}$

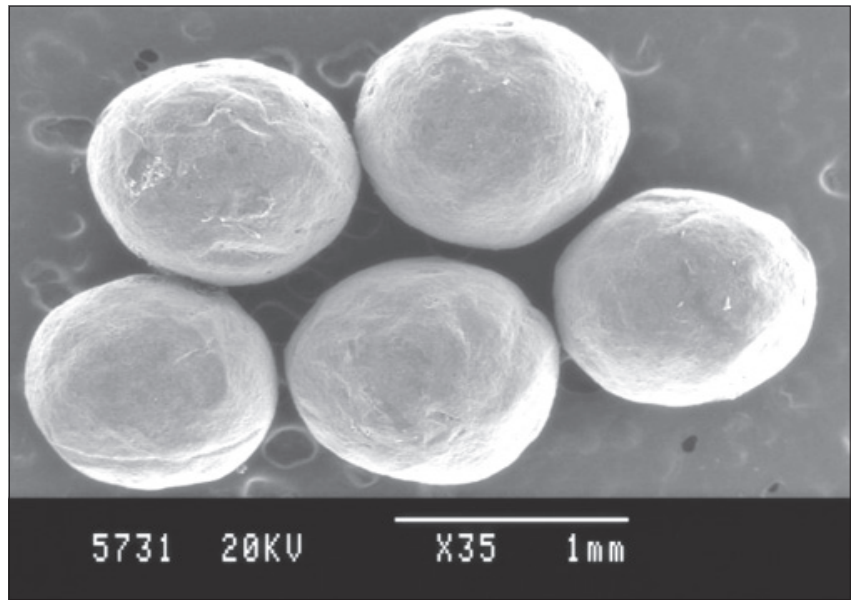

Figure 3: Scanning electron microscopy of optimized formulation F3(C)

and F3 formulation have size range $710-420 \mu \mathrm{m}$. ER coated pellets size ranges were shown in Table 3 .

\section{Drug release profile}

In this study, EC N 50, HPMC E5 and TEC were used in various ratios in order to control the drug release rate. Dissolution results (Figure 4) obtained from drug release studies showed that F1 (A) formulation prepared from sugar spheres (\#25/30) having 11\% coating of EC N50: HPMC E5 (70:30) shows faster release when compared with innovator. F1 (B) has 14\% coating of the same formulation, now the release rate was controlled, but not comparable to innovator's drug release profile. In formulation F1 (C) the ratio of polymers was changed, but now due to increase concentration of EC N50 the release profile slows down. ${ }^{24}$

In formulation, F2 sugar spheres (\#30/35) were used because as size decreases the surface area to volume ratio of the particle increases, i.e., the release rate increases, 
hence in F2 (A) EC N50 coating was done to control the release, but fines generation were more and also the release profile was found to be inappropriate. In F3 formulation sugar spheres (\#40/50) were used because water penetration in the smallest particle is quicker due to short distance from the surface to the center of the particle. F3 (A) has EC N50:HPMC E5 coating, but release rate was faster due to smaller size sugar spheres, so in order to control the release TEC was used instead of HPMC E5 here as TEC ratio decreases release rate decrease, TEC acting as a pore former here and F3 (C) formulation release rate was found comparable to innovator's release profile.

\section{Comparison of release profile of optimized formulation with innovator's product}

Similar drug release profile of optimized formulation with Inderal LA was confirmed by calculation of two factors, i.e., difference factor $\left(f_{1}\right)$ and similarity factor $\left(f_{2}\right)$ from the dissolution profile in $0.1 \mathrm{~N} \mathrm{HCl}$ for $1.5 \mathrm{~h}$ followed by 6.8 $\mathrm{pH}$ phosphate buffer. ${ }^{25}$

$\mathrm{f}_{1}=\left\{\left[\sum_{\mathrm{t}=1}^{\mathrm{n}}\left|\mathrm{R}_{\mathrm{t}}-\mathrm{T}_{\mathrm{t}}\right|\right] /\left[\sum_{\mathrm{t}=1}^{\mathrm{n}} \mathrm{R}_{\mathrm{t}}\right]\right\} \times 100$

$\mathrm{f}_{2}=50 \times \log \left\{\left[1+(1 / \mathrm{n}) \sum_{\mathrm{t}=1}^{\mathrm{n}}\left(\mathrm{R}_{\mathrm{t}}-\mathrm{T}_{\mathrm{t}}\right)^{2}\right]^{-0.5} \times 100\right\}$

Where $n$ is the sampling number,

$\mathrm{R}_{t}$ and $\mathrm{T}_{t}$ are the percent dissolved of the reference and test products at each time point $\mathrm{t}$.

Result of $\mathrm{f}_{1}$ (Difference factor) and $\mathrm{f}_{2}$ (Similarity factor) was found to be 1.95 and 99, respectively. It was found to be within the standards. The standards for similarity factor and difference factor are 50-100 and 0-15.

\section{Drug release kinetics}

In order to describe the kinetics of the release process of drug from optimized formulation F3 (C) the data were fitted with different kinetic model such as zero order,

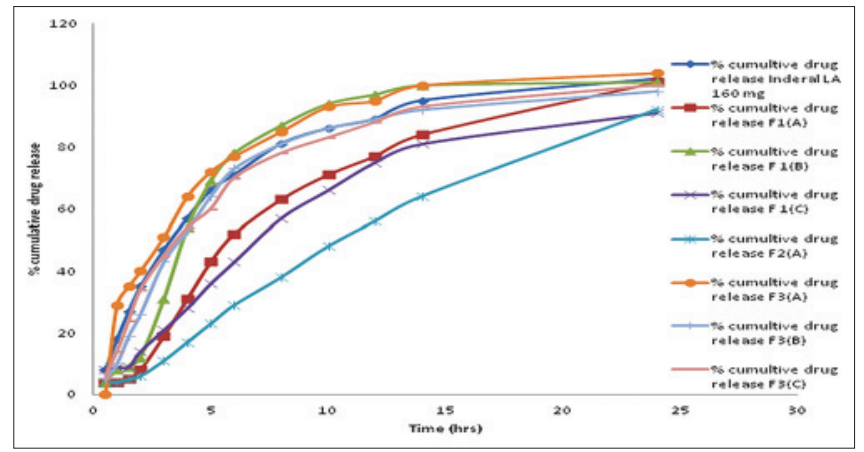

Figure 4: Comparative dissolution profile of different formulations with Inderal LA first order, Higuchi, and Korysmeyer-Peppas equation as shown in Table 4 . The correlation coefficient $\left(R^{2}\right)$ of the drug release from optimized formulation predominantly followed Higuchi model indicating diffusion dependent release process. Assuming that the polymeric formulation was non swellable and non-degradable, Peppas equation refers to mechanism of release as Fickian and nonFickian. ${ }^{26-28}$ Where $\mathrm{n}$ is the release exponent, an indication of the drug release mechanism. Release exponent value $(n)$ of Inderal LA and optimized formulation was 0.665 and 0.669 , so both Inderal and optimized formulation shows Fickian i.e., drug is released by diffusion.

\section{Stability studies}

The stability studies of the optimized formulation and Inderal LA were carried out according to ICH guidelines at $\left(40 \pm 2^{\circ} \mathrm{C} / 75 \% \mathrm{RH}\right)$ for 1 month $^{29}$ and found there was no change in the release profile before and after stability testing, Similarity factor $\left(f_{2}\right)$ was found to be 99 , respectively i.e., the formulation was stable (Figure 5).

\section{CONCLUSION}

From the calculation of $\mathrm{f}_{2}$ (Similarity factor) $=99 ; \mathrm{f}_{1}$ (Difference factor $)=1.95$, we concluded that the release

Table 4: Comparative study of Inderal LA and optimized formulation F3 (C) by kinetic models

\begin{tabular}{lcc}
\hline Model & Inderal LA $\mathbf{1 6 0} \mathbf{~ m g}$ & F3 (C) \\
\hline Peppas model & & \\
$N$ & 0.6653 & 0.6697 \\
$R^{2}$ & 0.9768 & 0.9769 \\
$\begin{array}{l}\text { Higuchi model } \\
R^{2}\end{array}$ & 0.9800 & 0.9770 \\
$\begin{array}{l}\text { Zero order } \\
R^{2}\end{array}$ & 0.8789 & 0.8791 \\
First order & & \\
$R^{2}$ & 0.9684 & 0.9379 \\
\hline
\end{tabular}

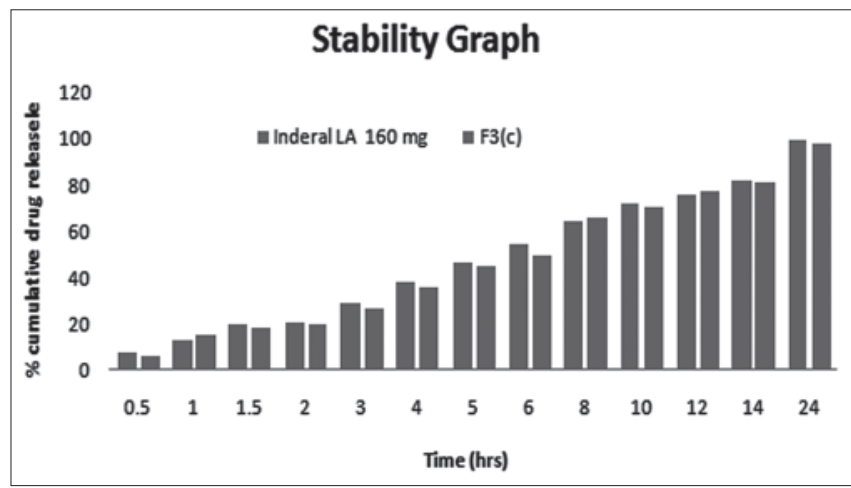

Figure 5: Result of stability studies of optimized formulation F3(C) and Inderal LA

Journal of Young Pharmacists Vol 6 • Issue 1 • Jan-Mar 2014 
profile of optimized formulation was comparable to that of the Inderal LA drug release profile and from the stability studies it was confirmed that the formulation was stable after 1 month.

\section{REFERENCES}

1. Hoffman BB. Catecholamine, Sympathomimetic drugs and adrenergic receptor antagonist. In: Gilman AG, editor. The Pharmacological Basis of Therapeutics. $5^{\text {th }}$ ed. New York: McGraw Hill; 1996. p. 249-54.

2. Halkin H, Vered I, Saginer A, Rabinowitz B. Once daily administration of sustained release propranolol capsules in the treatment of angina pectoris. Eur J Clin Pharmacol 1979;16:387-91.

3. Shivakumar HN, Patel R, Desai BG. Formulation optimization of propranolol hydrochloride microcapsules employing central composite design. Indian J Pharm Sci 2008;70:408-13.

4. Sahoo J, Murthy PN, Biswal S, Sahoo SK, Mahapatra AK. Comparative study of propranolol hydrochloride release from matrix tablets with Kollidon SR or hydroxy propyl methyl cellulose. AAPS Pharm Sci Tech 2008;9:577-82.

5. Bussemer T, Bdmeier R. Multiparticilate pulsatile drug delivery system. In: Benita S, editor. Microencapsulation Method and Industrial Applications. $2^{\text {nd }}$ ed. New York: Marcel Dekker; 1989. p. 79-94.

6. Chien YW. Fundamentals of rate controlled delivery. In: Chien YW, editor. Novel Drug Delivery Systems. $2^{\text {nd }}$ ed. New York: Marcel Dekker; 2000. p. 55-64.

7. Jantzen GM, Robinson JR. Sustained and controlled release drug delivery systems. In: Swarbrick J, editor. Modern Pharmaceutics. $3^{\text {rd }}$ ed. New York: Marcel Dekker; 2000. p. 575-95.

8. Cole G, Hogan J, Aulton ME. Film coating material and their properties. In: Mcginity J, editor. Pharmaceutical Coating Technology. $3^{\text {rd }}$ ed. UK: Taylor and Francis Ltd.; 1995. p. 13-5.

9. Kim MS, Jun SW, Lee S, Lee TW, Park JS, Hwang SJ. The influence of Surelease and sodium alginate on the in-vitro release of tamsulosin hydrochloride in pellet dosage form. J Pharm Pharmacol 2005;57:735-42.

10. Patil D, Sajeeth CI, Sirwani R, Santhi K. Modulation of combined release behaviors from a natural pellets and mini tablets in capsule system. Int J Pharm Biomed Sci 2011;2:649-60.

11. Dashevsky A, Kolter K, Bodmeier R. pH-independent release of a basic drug from pellets coated with the extended release polymer dispersion Kollicoat SR $30 \mathrm{D}$ and the enteric polymer dispersion Kollicoat MAE 30 DP. Eur J Pharm Biopharm 2004;58:45-9.

12. Almadi SN, Azar JZ, Varshosaz J, Ghaffari S, Kobarfard F. Preparation and evaluation of sustained release tramadol. Afr J Pharm Pharamacol 2012;6:2123-32.

13. Hariharan M, Gupta V, Price JC. Optimization of sustained-release tablet formulations: a four-component mixture experiment. Pharm Dev Technol 1997;2:365-71.

14. Frenning G, Tunón A, Alderborn G. Modelling of drug release from coated granular pellets. J Control Release 2003;92:113-23.

15. Frohoff-Hülsmann MA, Lippold BC, McGinity JW. Aqueous ethyl cellulose dispersion containing plasticizers of different water solubility and hydroxypropyl methyl-cellulose as coating material for diffusion pellets II: properties of sprayed films. Eur J Pharm Biopharm 1999;48:67-75.

16. Siepmann F, Siepmann J, Walther M, MacRae RJ, Bodmeier R. Blends of aqueous polymer dispersions used for pellet coating: importance of the particle size. J Control Release 2005;105:226-39.

17. FDA-Food and drug Administration, Center for Drug Evaluation and Research (CDER). Guidance for Industry, Dissolution Testing of Immediate Release Solid Oral Dosage Forms, 1997c. Available from: http://www.fda. gov/cder/guidance.htm. [Last Accessed date: 03-05-14].

18. Herman J, Remon JP, Lefebvre R, Bogaert M, Klinger GH, Schwartz JB. The dissolution rate and bioavailability of hydrochlorothiazide in pellet formulations. J Pharm Pharmacol 1988;40:157-60.

19. Banker GS, Anderson NR. Tablets. In: Lachman L, editor. The Theory and Practice of Industrial Pharmacy. $3^{\text {rd }}$ ed. Mumbai: Varghese Publishing House; 2009. p. 301-3.

20. Ong KT, Rege PR, Rajabi siabhoomi AR. Effect of hyperomellose as a pore former in aqueous ethylcellulose dispersion: Characterization of dispersion properties. Colorcon, USA: Controlled Release Society; 2006. p. 1-4.

21. Ozturk AG, Ozturk SS, Palsson BO, Wheatley TA, Dressman JB. Mechanism release from pellets coated with an ethyl cellulose based film. J Control Release 1990;14:203-13.

22. Mafadi SE, Hayert M, Poncelet D. Fluidization control in the Wurster coating process. Chem Ind 2003;57:641-4.

23. Wong D, Bodmeier R. Flocculation of aqueous colloidal ethyl cellulose dispersion (Aquacoat) with a water-soluble polymer, hydroxypropyl methyl cellulose. Eur J Pharm Biopharm 1996;42:12-5.

24. Robinson RJ. Controlled release drug delivery systems. In: Gennaro AF, editor. Remington: The Science and Practice of Pharmacy. $20^{\text {th }}$ ed. New Delhi: B.I. Publications Pvt. Ltd.; 2000. p. 903-7.

25. Vyas P, Khar RK. Controlled Drug Delivery - Concept and Advances. New Delhi: Vallabh Prakashan; 2001. p. 5-25.

26. Ford JL, Mitchell K, Rowe P, Armstrong DJ, Elliott PN, Rostron C, et al. Mathematical modeling of drug release from hydroxypropyl methylcellulose matrices: effect of temperature. Int J Pharm 1991;71:95-104.

27. Higuchi T. Mechanism of sustained-action medication. Theoretical analysis of rate of release of solid drugs dispersed in solid matrices. J Pharm Sci 1963;52:1145-9.

28. Korsmeyer RW, Gurny R, Doelker E, Buri P, Peppas NA. Mechanism of solute release from porous hydrophilic polymers. Int J Pharm 1983;15:25-35.

29. ICH guideline for immediate release, Center for Drug Research (CDER) Orange Book, January 1999. Available from: http://www.fda.gov/cder/ guidance/index.htm. [Last accessed date: 03-05-14]. 